\title{
Gender-related Differences in Target Organ Damage in Untreated Patients with Essential Hypertension
}

\author{
Makoto Saitoh, Hideya Nishimura, Toshiro Tanaka and Teruo Kondoh
}

\begin{abstract}
We examined the gender-related differences in target organ damage in 220 untreated patients with essential hypertension (106 men and 114 women). As the indices of target organ damage, we examined the left ventricular mass index and the intima-media thickness in the carotid and femoral arteries obtained from echocardiography. In a multiple regression model, there was a significant positive correlation between the intimamedia thickness and age in both groups. In men, there was a significant positive correlation between the left ventricular mass index and age, as well as the diastolic blood pressure, and body mass index. In women, there was a significant positive correlation between the left ventricular mass index and age, as well as plasma renin activity and smoking. In conclusion, there are gender-related differences in the contributing factors, which relate to left ventricular hypertrophy in patients with essential hypertension.
\end{abstract}

Key words: intima-media thickness, left ventricular hypertrophy, plasma renin activity, smoking

(DOI: 10.2169/internalmedicine.45.1503)

\section{Introduction}

Recently, the differential impact of gender on the occurrence, prognosis and the response to treatment in cardiovascular disease has been reported (1-3). Despite an overall reduction in the death rate due to cardiovascular disease in the United States over the last several decades, the rate of decline is less for women than men (1). Due to an aging population, the absolute number of deaths due to cardiovascular disease in women is actually increasing (1). In the CADILLAC trial, the higher mortality rate in women compared with men after interventional treatment for acute myocardial infarction was reported (2). In the BEST study for the patients with heart failure, there was a trend for better survival in men than women in the ischemic patients (3).

As in men, the strong association between hypertension and cardiovascular disease in women has been demonstrated by a number of prospective studies $(4,5)$. In the general population, the target organ damage, such as left ventricular hypertrophy (LVH), the intima-media thickness (IMT) of the carotid artery and proteinuria are directly associated with an increased risk of cardiovascular disease (6-9). To our knowl- edge, there are few reports about the gender-related differences in the prevalence of target organ damage and the contributing factors to target organ damage in the patients with essential hypertension.

We speculated the possibility of gender-specific therapies in the female patients with essential hypertension. In this study, we examined the gender-related differences in target organ damage and the related factors in untreated patients with essential hypertension.

\section{Methods}

The subjects were 220 patients with essential hypertension who were consecutively referred to the Division of Cardiology, the Department of Internal Medicine, Nishio Municipal Hospital between April 1997 and October 2004 (106 men and 114 women, mean age $55 \pm 10$ years). All of the patients were previously untreated. The blood pressure was measured with an arm-cuff and a mercury sphygmomanometer after the patient had been resting in the sitting position for 5 minutes. Systolic and diastolic blood pressure measurements were taken as the first and fifth phase of the Korotkoff sounds, respectively. Hypertension was defined as

${ }^{1}$ Division of Cardiology, Department of Internal Medicine, Nishio Municipal Hospital, Nishio

Received for publication July 26, 2005; Accepted for publication December 22, 2005

Correspondence to Makoto Saitoh, Division of Cardiology, the Department of Internal Medicine, Nishio Municipal Hospital, 6 Kamiawara Kumami-cho, Nishio 445-8510 
Table 1. Clinical Characteristics in the 220 Hypertensive Patients and Comparison between Men and Women

$\begin{array}{lccl} & \text { All } & \text { Men } & \text { Women } \\ & (n=220) & (n=106) & (n=114) \\ \text { Age } & 55 \pm 10 & 54 \pm 11 & 56 \pm 9 \\ \text { Sex (men/women) } & 106 / 114 & & \\ \text { Menopause in women } & 75(66 \%) & & \\ \text { SBP (mmHg) } & 163 \pm 20 & 161 \pm 20 & 165 \pm 19 \\ \text { DBP (mmHg) } & 97 \pm 12 & 98 \pm 12 & 96 \pm 11 \\ \text { Pulse rate(/min) } & 70 \pm 12 & 68 \pm 13 & 71 \pm 10 \\ \text { BMl (Kg/m2) } & 24.6 \pm 3.4 & 25.0 \pm 3.3 & 24.3 \pm 3.5 \\ \text { Duration of hypertension } & 3.7 \pm 6.6 & 3.8 \pm 7.6 & 3.6 \pm 5.6 \\ \text { (year) } & & & \\ \text { Smoking } & 62(28 \%) & 49(46 \%) & 13(11 \%)^{* * *} \\ \text { Plasma renin activity } & 0.97 \pm 0.78 & 1.19 \pm 0.94 & 0.76 \pm 0.54^{* \cdots *} \\ \text { Plasma aldosterone (pg/ml) } & 85.7 \pm 38.8 & 92 \pm 38 & 80 \pm 39^{*} \\ \text { Fasting glucose (mg/dl) } & 107 \pm 31 & 111 \pm 40 & 104 \pm 21 \\ \text { Hemoglobin A1c (\%) } & 5.3 \pm 0.8 & 5.3 \pm 0.9 & 5.2 \pm 0.7 \\ \text { Total cholesterol (mg/dl) } & 210 \pm 34 & 204 \pm 32 & 216 \pm 35^{*} \\ \text { Triglyceride (mg/dl) } & 130 \pm 78 & 152 \pm 95 & 110 \pm 49^{* \cdots *} \\ \text { HDL-cholesterol (mg/dl) } & 58 \pm 17 & 55 \pm 19 & 62 \pm 15^{* *} \\ \text { Uric acid (mg/dl) } & 5.3 \pm 1.4 & 6.0 \pm 1.2 & 4.5 \pm 1.1^{* *} \\ & & & \end{array}$

BMI: body mass index, DBP: diastolic blood pressure, SBP: systolic blood pressure. $" p<0.05, \quad " p<0.01, \quad \cdots+p<0.0001$ vs, men.

a systolic blood pressure $\geq 140 \mathrm{mmHg}$ and/or diastolic blood pressure $\geq 90 \mathrm{mmHg}$ on two measurements taken with a 1-week interval. Patients who had evidence of secondary hypertension, valvular, coronary or primary myocardial disease, or a serum creatinine concentration $>2 \mathrm{mg} / \mathrm{dl}$ were excluded.

Normotension was defined as systolic blood pressure < $130 \mathrm{mmHg}$ and diastolic blood pressure $<85 \mathrm{mmHg}$. Twenty-four age-and sex-matched normotensive subjects (12 men and 12 women, mean age $54 \pm 10$ years) who had no history of hypertension and no evidence of cardiac disease served as controls.

As indices of target organ damage in the hypertensive patients, we examined left ventricular hypertrophy, atherosclerotic changes in the carotid and femoral arteries, retinal damage and proteinuria.

The hypertensive patients and normal subjects underwent echocardiographic measurement. Echocardiographic studies were carried out using a SONOS 4500 echocardiograph with a 3.5-MHz transducer (Philips Medical Systems, Bothell, WA) in the left lateral decubitus position. Left ventricular dimensions were taken from at least three cycles according to the Penn convention measurements $(10,11)$. These included the left ventricular end-diastolic diameter (LVEDD), the interventricular septal thickness (IVST) and the posterior wall thickness (PWT). The left ventricular mass was derived from the Penn conventions and the following formula: left ventricular mass $(g)=1.04 \quad\left[(\text { LVEDD+IVST+PWT })^{3}\right.$ LVEDD ${ }^{3}$ ]-13.6 (10,11). The left ventricular mass index (LVMI) was calculated by dividing the left ventricular mass by the body surface area. For the measurement of relative wall thickness,
Table 2. Target Organ Damage in the 220 Hypertensive Patients and Comparison between Men and Women

\begin{tabular}{|c|c|c|c|}
\hline & $\begin{array}{l}\text { ALL } \\
(n=220)\end{array}$ & $\begin{array}{l}\text { Men } \\
(n=106)\end{array}$ & $\begin{array}{l}\text { Women } \\
(n=114)\end{array}$ \\
\hline \multicolumn{4}{|c|}{ Echocardiographic findings: } \\
\hline LVMI $\left(g / \mathrm{m}^{2}\right)$ & $122 \pm 42$ & $136 \pm 46$ & $110 \pm 34 * \cdots$ \\
\hline LVH $(\%)$ & $139(64 \%)$ & $74(70 \%)$ & $65(57 \%)^{*}$ \\
\hline RWT & $0.44 \pm 0.08$ & $0.44 \pm 0.08$ & $0.43 \pm 0.09$ \\
\hline \multicolumn{4}{|c|}{ Retinal vascular change: } \\
\hline \multicolumn{4}{|c|}{ (Keith-Wagener-Barker) } \\
\hline grade 0 & $47(21) \%$ & $21(20 \%)$ & $26(23 \%)$ \\
\hline grade 1 & $105(48 \%)$ & $49(46 \%)$ & $56(49 \%)$ \\
\hline grade 2 & $61(28 \%)$ & $34(32 \%)$ & $27(24 \%)$ \\
\hline grade 3 & $7(3 \%)$ & $2(2 \%)$ & $5(4 \%)$ \\
\hline Proteinuria & $27(12 \%)$ & $16(15 \%)$ & $11(10 \%)$ \\
\hline \multicolumn{4}{|c|}{ Vascular echographic findings: } \\
\hline \multicolumn{4}{|l|}{ Carotid artery } \\
\hline $\max$ IMT $(\mathrm{mm})$ & $1.09 \pm 0.65$ & $1.14 \pm 0.75$ & $1.04 \pm 0.54$ \\
\hline \multicolumn{4}{|l|}{ Femoral artery } \\
\hline $\max$ IMT $(\mathrm{mm})$ & $1.3 \pm 0.8$ & $1.44 \pm 0.83$ & $1.18 \pm 0.76^{*}$ \\
\hline \multicolumn{4}{|c|}{ IMT: intima-media thickness, LVH: left ventricular hypertrophy. } \\
\hline \multicolumn{4}{|c|}{ LVMI: left ventricular mass index, RWT: relative wall thickness. } \\
\hline \multicolumn{4}{|c|}{$" p<0.05, \cdots+p<0,0001$ vs, men } \\
\hline
\end{tabular}

LVEDD, IVST and PWT were measured according to the American Society of Echocardiography guidelines (12). Relative wall thickness was calculated as follows: relative wall thickness $($ RWT $)=($ IVST+PWT/LVEDD $)$.

In hypertensive patients, we examined the ultrasonographic scanning of the carotid and femoral arteries to record the most advanced atherosclerotic lesion according to the methods of Wendelhag et al $(13,14)$. The bilateral carotid and femoral arteries were investigated in the longitudinal and the transverse projections using a SONOS 4500 echocardiograph with a $7.5-\mathrm{MHz}$ transducer. The IMT was defined as the distance from the leading edge of the lumenintima interface to the leading edge of the media-adventitia interface of the far wall. The measurement of IMT in the common carotid artery was made along a 10-mm-long section just proximal to the carotid bulb. In the common femoral artery, measurements were made along a 15-mm-long section proximal to the bifurcation. At each longitudinal projection, IMT was measured from the site of the greatest thickness. The three determinations were averaged.

An ophthalmologist who was blinded to the blood pressure levels and echocardiographic data carried out the ophthalmoscopic examination. The retinopathic changes were assigned to four categories according to the Keith-WagenerBarker scale (15).

Midstream urine samples collected in the morning after an overnight fast were immediately examined for protein in a semiquantitative fashion, and scored as,,,- \pm+++ or +++ , using a chemical reagent strip, the "Multistix 9 SG" (BayerSankyo Co., Tokyo, Japan).

In the hypertensive patients, we examined the clinical characteristics that are thought to be related to target organ 
Table 3. Univariate Correlation of the LVMI and Clinical Variables in the Hypertensive Patients

\begin{tabular}{|c|c|c|c|}
\hline & $\begin{array}{l}\text { All } \\
(n=220)\end{array}$ & $\begin{array}{l}\text { Men } \\
(n=106)\end{array}$ & $\begin{array}{l}\text { Women } \\
(n=114)\end{array}$ \\
\hline Age & $0.183^{* *}$ & $0.251^{* *}$ & $0.192^{*}$ \\
\hline Male gender & $0.310^{* \ldots *}$ & & \\
\hline SBP & $0.223^{* *}$ & $0.363^{* \cdots *}$ & 0.148 \\
\hline DBP & $0.226^{\cdots *}$ & $0.311^{* *}$ & 0.082 \\
\hline BMI & $0.226^{* \cdots}$ & $0.258^{* *}$ & 0.146 \\
\hline $\begin{array}{l}\text { Plasma renin } \\
\text { activity }\end{array}$ & $0.225^{\cdots *}$ & 0.112 & $0.242^{* *}$ \\
\hline Plasma aldosterone & 0.083 & 0.009 & 0.070 \\
\hline Total cholesterol & $-0.152^{*}$ & 0.136 & 0.076 \\
\hline Triglyceride & 0.068 & 0.028 & 0.012 \\
\hline HDL-cholesterol & $0.145^{*}$ & 0.092 & 0.093 \\
\hline Uric acid & $0.204^{* *}$ & 0.043 & 0.045 \\
\hline Smoking & $0.291^{\ldots \ldots}$ & 0.183 & $0.311^{\cdots * *}$ \\
\hline
\end{tabular}

Table 4. Univariate Correlation of the the MAX IMT of the Femoral Artery and Clinical Variables in the Hypertensive Patients

$\begin{array}{lccc} & \begin{array}{l}\text { All } \\ (\mathrm{n}=220)\end{array} & \begin{array}{l}\text { Men } \\ (\mathrm{n}=106)\end{array} & \begin{array}{l}\text { Women } \\ (\mathrm{n}=114)\end{array} \\ & 0.356^{\cdots \cdots} & 0.433^{\cdots \cdots} & 0.316^{\cdots} \cdot \\ \text { Age } & 0.164^{*} & & \\ \text { Male gender } & 0.074 & 0.122 & 0.060 \\ \text { SBP } & 0.103 & 0.109 & 0.126 \\ \text { DBP } & 0.006 & 0.087 & 0.060 \\ \text { BMI } & 0.040 & 0.119 & 0.047 \\ \text { Plasma renin } & & & \\ \text { activity } & 0.089 & 0.132 & 0.103 \\ \text { Plasma aldosterone } & 0.070 & 0.058 & 0.030 \\ \text { Total cholesterol } & 0.019 & 0.031 & 0.020 \\ \text { Triglyceride } & 0.130 & 0.169 & 0.012 \\ \text { HDL-cholesterol } & 0.099 & 0.076 & 0.111 \\ \text { Uric acid } & 0.124 & 0.018 & 0.145 \\ \text { Smoking } & & & \end{array}$

$" p<0.05, \cdots p<0.001, \cdots p<0.0001$.

Other abbreviations as in Tables 1 and 2.

damage, i.e., age, sex, systolic blood pressure, diastolic blood pressure, body mass index, duration of hypertension, smoking, plasma renin activity, plasma aldosterone concentration, fasting blood glucose concentration, hemoglobin A1c, serum total cholesterol concentration, serum triglyceride concentration, serum high-density lipoprotein (HDL)cholesterol concentration and serum uric acid concentration. The body mass index was selected as a measure of obesity,
Table 5. Stepwise Multiple Regression Analysis of Independent Variables that May Influence the LVMI and the IMT of the Femoral Artery in the 220 Hypertensive Patients

\begin{tabular}{|c|c|c|}
\hline & $\mathrm{F}$ & $\begin{array}{l}\text { Partial correlation } \\
\text { coefficient }\end{array}$ \\
\hline \multicolumn{3}{|l|}{ LVMI } \\
\hline Age & 36.401 & 0.364 \\
\hline Male gender & 6.202 & 0.158 \\
\hline DBP & 17.405 & 0.248 \\
\hline BMI & 11.329 & 0.196 \\
\hline Plasma renin activity & 7.149 & 0.163 \\
\hline Total cholesterol & 4.936 & -0.128 \\
\hline Smoking & 11.645 & 0.209 \\
\hline \multicolumn{3}{|c|}{ Max IMT of femoral artery } \\
\hline Age & 36.616 & 0.377 \\
\hline Male gender & 10.564 & 0.202 \\
\hline \multicolumn{3}{|l|}{ Multivariate prediction: } \\
\hline \multirow{3}{*}{\multicolumn{3}{|c|}{$\begin{array}{l}\text { LVMI }=-92.769+1.477 \text { (age) }+13.203 \text { (male gender) }+0.89(\mathrm{DBP})+2.414 \\
(\mathrm{BMI})+8.706 \text { (plasma renin activity) }-0.156 \text { (total cholesterol) }+19.415 \\
\left(\text { smoking); adjusted } \mathrm{R}^{2}=0.311, p<0.0001 .\right.\end{array}$}} \\
\hline & & \\
\hline & & \\
\hline \multicolumn{3}{|c|}{$\begin{array}{l}\text { Max IMT of femoral artery }=-0.468+0.029 \text { (age) }+0.323 \text { (male gender); } \\
\text { adjusted } R^{2}=0.160, \quad p<0.0001 \text {. }\end{array}$} \\
\hline
\end{tabular}

Table 6. Stepwise Multiple Regression Analysis of Independent Variables that may Influence the LVMI and the IMT of the Femoral Artery in the 106 Male Hypertensive Patients

$\begin{array}{lcc}\text { LVMI } & \text { F } & \begin{array}{l}\text { Partial correlation } \\ \text { coefficient }\end{array} \\ \text { Age } & 23.364 & 0.425 \\ \text { DBP } & 18.681 & 0.371 \\ \text { BMI } & 13.003 & 0.310 \\ \text { Max IMT of femoral artery } & & \\ \text { Age } & 23.977 & 0.433\end{array}$

Multivariate prediction:

LV mass index $=-203.775+1.734$ (age) $+1.399(\mathrm{DBP})+4.326(\mathrm{BMI})$; adjusted $R^{2}=0.311, p<0.0001$

Max IMT of femoral artery $=-0.295+0.032$ (age); adjusted $R^{2}=0.180$ $p<0.0001$.

Abbreviations as in Tables 1 and 2.

determined as weight $(\mathrm{kg})$ divided by height $(\mathrm{m})$ squared.

The venous blood samples were obtained after 30 minutes of rest in the supine position. Plasma renin activity and aldosterone concentration were measured by radioimmunoassay with a gamma counter. The blood glucose concentration was measured using the glucose oxidase immobilized membrane-hydrogen peroxide electrode peak acceleration method with an autoanalyzer (ADAMS-Glucose GA-1170 ARKRAY Co., Kyoto, Japan). Hemoglobin A1c was analyzed on the ADAMS-A1c HA-8160(ARKRAY Co.) based on the HPLC method. The serum total cholesterol and uric acid concentrations were measured by novel enzymatic 
Table 7. Stepwise Multiple Regression Analysis of Independent Variables that may Influence the LVMI and the IMT of the Femoral Artery in the 114 Female Hypertensive Patients

\begin{tabular}{|c|c|c|}
\hline & $\mathrm{F}$ & $\begin{array}{l}\text { Partial correlation } \\
\text { coefficient }\end{array}$ \\
\hline \multicolumn{3}{|l|}{ LVMI } \\
\hline Age & 10.485 & 0.284 \\
\hline Plasma renin activity & 9.091 & 0.268 \\
\hline Smoking & 11.226 & 0.288 \\
\hline \multicolumn{3}{|c|}{ Max IMT of femoral artery } \\
\hline Age & 12.459 & 0.316 \\
\hline \multicolumn{3}{|l|}{ Multivariate prediction: } \\
\hline \multicolumn{3}{|c|}{$\begin{array}{l}\text { LV mass index }=36.060+1.020 \text { (age) }+16.789 \text { (plasma renin activity) }+30.346 \\
\text { (smoking): }\end{array}$} \\
\hline \multicolumn{3}{|c|}{$\begin{array}{l}\text { Max IMT of femoral artery }=-0.260+0.025 \text { (age); adjusted } R^{2}=0.092 \\
p<0.001\end{array}$} \\
\hline
\end{tabular}

methods with an auto-analyzer (HITACHI-7180, Hitachi Medical Co., Tokyo, Japan). Using the same autoanalyzer, the serum triglyceride concentrations were measured using the free glycerol elimination enzymatic method, and the serum HDL-cholesterol concentration was measured using a chemical modification enzymatic method.

The data are expressed as mean values \pm 1 SD. The statistical evaluation was performed with the unpaired t-test or chi-square test. Univariate correlations were analyzed using Pearson's correlation coefficient. We performed a forward stepwise regression analysis to select appropriate independent variables producing the highest partial correlation with the indices of target organ damage in the hypertensive patients. A p value of less than 0.05 was taken to indicate a significant difference.

\section{Results}

In 24 age- and sex-matched normotensive subjects, the LVMI in the men was $81 \pm 16 \mathrm{~g} / \mathrm{m}^{2}$, and the LVMI in the women was $78 \pm 10 \mathrm{~g} / \mathrm{m}^{2}$. RWT was $0.33 \pm 0.04$. The upper normal limits for the LVMI (estimated as 2 SD above the mean values of the 24 normal subjects) were $113 \mathrm{~g} / \mathrm{m}^{2}$ in men and $98 \mathrm{~g} / \mathrm{m}^{2}$ in women. $\mathrm{LVH}$ was considered present if the LVMI exceeded $113 \mathrm{~g} / \mathrm{m}^{2}$ in men or $98 \mathrm{~g} / \mathrm{m}^{2}$ in women.

Table 1 shows the clinical characteristics in the 220 hypertensive patients. In the 114 hypertensive women, 75 women $(66 \%)$ were post-menopause. Table 2 shows the indices of target organ damage in the 220 hypertensive patients. Sixty-four percent of all the patients had LVH according to echocardiography.

Table 1 shows a comparison of the clinical characteristics between men and women. Age, systolic blood pressure, diastolic blood pressure, pulse rate, body mass index, duration of hypertension, fasting glucose concentration and hemoglo- bin A1c were equal between the men and women. Smoking was more prevalent in men than in women. Plasma renin activity, plasma aldosterone concentration, plasma triglyceride concentration and plasma uric acid were significantly higher in men than in women. Contrary to these findings, the plasma total cholesterol concentration and plasma HDLcholesterol concentration were significantly higher in women than in men.

Table 2 shows a comparison of the indices of target organ damage between men and woman. LVMI was significantly higher in men than in women. LVH was more prevalent in men than in women. RWT, the retinal vascular change and the incidence of proteinuria were equal between the two groups. Although the max IMT of the carotid artery was equal between the two groups, the max IMT of the femoral artery was significantly thicker in men than in women.

Table 3 shows the results of the univariate correlation of the LVMI and clinical variables in the hypertensive patients. In all hypertensive patients, age, male gender, systolic blood pressure, diastolic blood pressure, body mass index, plasma renin activity, HDL-cholesterol, uric acid and smoking correlated significantly with the LVMI. In men, age, systolic blood pressure, diastolic blood pressure and body mass index correlated significantly with the LVMI. In women, age, plasma renin activity and smoking correlated significantly with the LVMI.

Table 4 shows the results of the univariate correlation of the max IMT of the femoral artery and clinical variables in the hypertensive patients. In all hypertensive patients, age and male gender correlated significantly with the max IMT. In both men and women, only age correlated significantly with the max IMT.

Table 5 shows the results of the multivariate analysis of independent variables that may influence the LVMI and the max IMT of the femoral artery in the 220 hypertensive patients. Age, male gender, diastolic blood pressure, body mass index, plasma renin activity and smoking were positively related to the LVMI. In the max IMT of the femoral artery, age and male gender were significantly associated.

Table 6 shows the results of the multivariate analysis of independent variables that may influence the LVMI and the max IMT of the femoral artery in the 106 male hypertensive patients. Age, diastolic blood pressure and body mass index were positively related to LVMI. Only age was positively related to the max IMT of the femoral artery.

Table 7 shows the results of the multivariate analysis of independent variables that may influence the LVMI and the max IMT of the femoral artery in the 114 female hypertensive patients. Age, plasma renin activity and smoking positively related to LVMI. In the max IMT of the femoral artery, only age was significantly associated.

\section{Discussion}

In our study, we found that LVH and the max IMT of the femoral artery are more prominent in men than in women in 
the hypertensive patients. Next, we found that there were differences of the factors related to LVH between men and women in the hypertensive patients. In LVMI, age, plasma renin activity and smoking were positively related in women. Contrary to these findings, age, diastolic blood pressure and body mass index related positively to LVMI in men. Third, in the IMT of femoral arteries, only age related positively in both men and women.

Recently, there have been several reports concerning the gender-related differences in the influence of left ventricular hypertrophy on survival $(16,17)$. It was reported that LVH has a greater impact on survival in women than in men both in the patients with and without coronary artery disease (16, 17). Liao et al reported a gender-related difference in the contribution of LVH to mortality in the 436 consecutive patients free of angiographic coronary artery disease (17). For cardiac death, the relative risk of $\mathrm{LVH}$ was 1.3 and 7.5 in men and women, respectively. There was a significant gender-related difference in the contribution of LVH to survival. We thought that it was important to evaluate the gender-related differences of contributing factors to LVH in the hypertensive patients.

There have been several reports about the factors related to LVH, such as blood pressure (clinic blood pressure, 24hour ambulatory blood pressure, blood pressure during stressful conditions), sympathetic nervous activity, plasma renin activity, plasma aldsterone concentration, body mass index and aging (18-24). The two major factors in the pathogenesis of $\mathrm{LVH}$ postulated on the basis of experimental results are hemodynamic and non-hemodynamic factors (24). Blood pressure is thought to be a hemodynamic factor. Plasma renin activity is thought to be non-hemodynamic. In our study, not a hemodynamic factor, but a nonhemodynamic factor, was related to $\mathrm{LVH}$ in the hypertensive women.

It is well known that the plasma renin profile holds much important information for therapy and prognosis in hypertensive patients (25-29). It was reported that a high plasma renin activity in hypertensive patients is associated with the risk of myocardial infarction $(25,26)$. Alderman et al reported a prospective trial involving 1717 patients with mildto-moderate hypertension followed-up for 8.3 years (25). The heart attack rate of the high-renin patients was 3.2 times higher than that of the low-renin patients (25). There is much experimental and clinical evidence relating plasma renin-angiotensin levels to cardiovascular damage (26).

Conversely, several reports have suggested that salt sensitivity increases the risk of cardiovascular disease and all causes of mortality (27-29). It was reported that low-renin hypertension is associated with salt sensitivity $(30,31)$. Morimoto et al assessed the salt sensitivity in about 350 Japanese patients with essential hypertension (28). They reported that LVH was found more frequently in the saltsensitive group than in the non-salt-sensitive group, and cardiovascular events occurred more frequently in patients with salt-sensitive hypertension (28). These results seem to con- flict with the results of the study by Alderman et al $(25,28)$.

In the present study, the plasma renin activity was significantly higher in men than in women, and the plasma renin activity was related to LVH only in the hypertensive women. Our study results showing that target organ damage was more severe in men than in women may be explained partially by the high plasma renin activity in men. Because we did not examine the protocol for the diagnosis of salt sensitivity, we cannot evaluate the influence of salt-sensitive hypertensive patients on our study results. Although we cannot explain the exact reason for the positive relationship between plasma renin activity and LVH in the hypertensive women, there is the possibility that the plasma renin profile has key information to appropriate gender-specific hypertensive therapy and prognosis.

There have been several reports concerning the genderspecific treatment of hypertension (32-34). Gueyffier et al reported the meta analysis of hypertensive individual patient data according to sex, treatment with beta-blockers and thiazide diuretics (33). In their study, the absolute risk reduction due to treatment was not the same for women and men (33). For women, the absolute risk reduction was seen primarily for strokes, whereas in men, treatment prevented both strokes and coronary events (33). They concluded that the absolute benefit treatment for strokes and coronary events cannot be predicted across the sexes, and physicians need appropriate tools for predicting untreated risk in order to individualize hypertensive and other preventive therapies (33). Recently, Wassertheil-Smoller et al reported the association between cardiovascular outcomes and antihypertensive drug treatment in 30,219 older women (34). Among women with hypertension, but no history of cardiovascular disease, a 2drug-class regimen of calcium channel blockers plus diuretics was associated with a higher risk of cardiovascular disease mortality vs. beta-blockers plus diuretics (34). Risks were similar for ACE inhibitors plus diuretics and betablockers plus diuretics (34). Although the role of the plasma renin activity in the prognosis was not evaluated in these studies, they suggested the possibility of gender-specific drug therapies in hypertensive patients $(33,34)$. Further studies for gender-specific treatment in hypertensive patients are needed.

Prescott et al reported that female smokers have a higher relative risk of myocardial infarction than male smokers, even after adjustment for major cardiovascular risk factors (35). Our study result of the relationship between LVH and smoking in hypertensive women may be related to the gender-related differences of the prognostic significances of smoking.

Stensland-Bugge et al examined the age and genderrelated differences in the relationship between inherited and lifestyle risk factors and subclinical carotid atherosclerosis in the general population (36). The carotid IMT is thicker in men than in women across all ages (36). Age, systolic blood pressure, total cholesterol, HDL cholesterol, body mass index and smoking were independent predictors of IMT in 
both sexes (36). These findings are compatible with our findings.

There are several limitations in our study. This was a retrospective study. Although the age between men and women was matched in our study, two-thirds of hypertensive women had undergone menopause. We were unable to examine the effect of menstruation in our study. We could not speculate about the reason why not carotid IMT, but only femoral IMT, was significantly different between both sexes. Although the condition of blood collection was equal between men and women, the plasma renin activity had been found to be affected by several factors, such as the sodium intake (22). We did not examine the indices of sodium intake. Recently, there have been several reports concerning the relationship between aldosterone and cardiac structure $(19,20)$. In our study, there was no significant relationship between LVH and the plasma aldosterone concentration either in men or women. The reason for this is not clear.

In conclusion, there are gender-related differences in the contributing factors, which relate to LVH in patients with essential hypertension. These differences, such as plasma renin activity, may have clinical implications for genderspecific treatment in hypertensive patients.

\section{References}

1. Mosca L, Manson JE, Sutherland SE, Langer RD, Manolio T. Barrett-Connor E. Cardiovascular disease in women: a statement for healthcare professionals from the American Heart Association. Writing Group. Circulation 96: 2468-2482, 1997.

2. Lansky AJ, Pietras C, Costa RA, et al. Gender differences in outcomes after primary angioplasty vs primary stenting with and without abciximab for acute myocardial infarction: Results of the Controlled Abciximab and Device Investigation to Lower Late Angioplasty Complications (CADILLAC) trial. Circulation 111: 1611-1618, 2005.

3. Ghali JK, Krause-Steinrauf HJ, Adams KF, et al. Gender differences in advanced heart failure: insights from the BEST study. J Am Coll Cardiol 42: 2128-2134, 2003.

4. Padwal R, Straus SE, McAlister FA. Evidence based management of hypertension: cardiovascular risk factors and their effects on the decision to treat hypertension: evidence based review. BMJ 322: 977-980, 2001.

5. Rich-Edwards JW, Manson JE, Hennekens CH, Buring JE. The primary prevention of coronary heart disease in women. $\mathrm{N}$ Engl $\mathrm{J}$ Med 332: 1758-1766, 1995.

6. Levy D, Garrison RJ, Savage DD, Kannel WB, Castelli WP. Prognostic implications of echocardiographically determined left ventricular mass in the Framingham Heart Study. N Engl J Med 322: 1561-1566, 1990.

7. O'Leary DH, Polak JF, Kronmal RA, Manolio TA, Burke GL, Wolfson SK Jr. for The Cardiovascular Health Study Collaborative Research Group. Carotid-artery intima and media thickness as a risk factor for myocardial infarction and stroke in older adults. N Engl J Med 340: 14-22, 1999.

8. Bots ML, Hoes AW, Koudstaal PJ, Hofman A, Grobbee DE. Common carotid intima-media thickness and risk of stroke and myocardial infarction: the Rotterdam Study. Circulation 96: 14321437, 1997.

9. Kannel WB, Stampfer MJ, Castelli WP, Verter J. The prognostic significance of proteinuria: The Framingham study. Am Heart J 108: 1347-1352, 1984.

10. Devereux RB, Alonso DR, Lutas EM, et al. Echocardiographic assessment of left ventricular hypertrophy: Comparison to necropsy findings. Am J Cardiol 57: 450-458, 1986.

11. Devereux RB, Reichek N. Echocardiographic determination of left ventricular mass in man. Anatomic validation of the method. Circulation 55: 613-618, 1977.

12. Sahn DJ, DeMaria A, Kisslo J, Weyman A. The Committee on Mmode Standardization of the American Society of Echocardiography. Recommendations regarding quantitation in M-mode echocardiography: Results of a survey of echocardiographic measurements. Circulation 58: 1072-1083, 1978.

13. Wendelhag I, Wiklund O, Wikstrand J. Atherosclerotic changes in the femoral and carotid arteries in familial hypercholesterolemia: ultrasonographic assessment of intima-media thickness and plaque occurrence. Arterioscler Thromb 13: 1404-1411, 1993.

14. Pignoli P, Tremoli E, Poli A, Oreste P, Paoletti R. Intimal plus medial thickness of the arterial wall: a direct measurement with ultrasound imaging. Circulation 74: 1399-1406, 1986.

15. Keith NM, Wagener HP, Barker NW. Some different types of essential hypertension: Their course and prognosis. Am J Med Sci 197: 332-343, 1939.

16. East MA, Jollis JG, Nelson CL, Marks D, Peterson ED. The influence of left ventricular hypertrophy on survival in patients with coronary artery disease: do race and gender matter? J Am Coll Cardiol 41: 949-954, 2003.

17. Liao Y, Cooper RS, Mensah GA, McGee DL. Left ventricular hypertrophy has a greater impact on survival in women than in men. Circulation 92: 805-810, 1995.

18. Saitoh M, Miyakoda H, Kitamura H, et al. Cardiovascular and sympathetic nervous response to dynamic exercise in patients with essential hypertension. Intern Med 31: 606-610, 1992.

19. Vasan RS, Evans JC, Benjamin EJ, et al. Relations of serum aldosterone to cardiac structure. Gender-related differences in the Framingham Heart Study. Hypertension 43: 957-962, 2004.

20. Yamamoto N, Yasue H, Mizuno Y, et al. Aldosterone is produced from ventricles in patients with essential hypertension. Hypertension 39: 958-962, 2002.

21. Duprez DA, Bauwens FR, De Buyzere ML, et al. Influence of arterial blood pressure and aldosterone on left ventricular hypertrophy in moderate essential hypertension. Am J Cardiol 71: 17A-20 A, 1993.

22. Schunkert H, Hense HW, Muscholl M, et al. Associations between circulating components of the renin-angiotensin-aldosterone system and left ventricular mass. Heart 77: 24-31, 1997.

23. Ren JF, Hakki AH, Kotler MN, Iskandrian AS. Exercise systolic blood pressure: A powerful determinant of increased left ventricular mass in patients with hypertension. J Am Coll Cardiol 5: 1224-1231, 1985.

24. Frohlich ED. Left ventricular hypertrophy, cardiac diseases and hypertension: Recent experiences. J Am Coll Cardiol 14: 15871594, 1989.

25. Alderman MH, Madhavan S, Ooi WL, Cohen H, Sealey JE, Laragh JH. Association of the renin-sodium profile with the risk of myocardial infarction in patients with hypertension. N Engl J Med 324: 1098-1104, 1991.

26. Laragh JH, Lewis K. Dahl Memorial Lecture. The renin system and four lines fo hypertension research. Nephron heterogeneity, the calcium connection, the prorenin vasodilator limb, and plasma renin and heart attack. Hypertension 20: 267-279, 1992.

27. Alderman MH. Salt, blood pressure and health: a cautionary tale. 
Int J Epidemiol 31: 311-316, 2002.

28. Morimoto A, Uzu T, Fujii T, et al. Sodium sensitivity and cardiovascular events in patients with essential hypertension. Lancet 350: 1734-1737, 1997.

29. Weinberger MH, Fineberg NS, Fineberg SE, Weinberger M. Salt sensitivity, pulse pressure, and death in normal and hypertensive humans. Hypertension 37: 429-432, 2001.

30. Weinberger MH. Salt sensitivity of blood pressure in humans. Hypertension 27: 481-490, 1996.

31. Fisher NDL, Hurwitz S, Ferri C, Jeunemaitre X, Hollenberg NK, Williams GH. Altered adrenal sensitivity to angiotensin II in lowrenin essential hypertension. Hypertension 34: 388-394, 1999.

32. August P, Oparil S. Hypertension in women. J Clin Endocrinol Metab 84: 1862-1866, 1999

33. Gueyffier F, Boutitie F, Boissel JP, et al. Effect of antihypertensive drug treatment on cardiovascular outcomes in women and men. A meta-analysis of individual patient data from randomized, controlled trials. The INDANA Investigators. Ann Intern Med 126: 761-767, 1997.

34. Wassertheil-Smoller S, Psaty B, Greenland P, et al. Association between cardiovascular outcomes and antihypertensive drug treatment in older women. JAMA 292: 2849-2859, 2004.

35. Prescott E, Hippe M, Schnohr P, Hein HO, Vestbo J. Smoking and risk of myocardial infarction in women and men: longitudinal population study. BMJ 316: 1043-1047, 1998.

36. Stensland-Bugge E, B $\phi$ naa KH, Joakimsen O. Age and sex differences in the relationship between inherited and lifestyle risk factors and subclinical carotid atherosclerosis: the Troms $\phi$ study. Atherosclerosis 154: 437-448, 2001.

(C) 2006 The Japanese Society of Internal Medicine

http://www.naika.or.jp/imindex.html 